\title{
The effect of psychosocial stress on single mothers' smoking
}

\author{
Stefanie Sperlich*, Mercy Nyambura Maina and Dorothee Noeres
}

\begin{abstract}
Background: Evidence suggests an increased risk of smoking among single mothers as compared to their cohabitating counterparts. This article examines the role of psychosocial stress in mediating the relationship between single motherhood and smoking.

Methods: Data were derived from a cross-sectional population based sample of German women $(n=3129)$ with underage children (0-18 years of age). Perceived stress was measured with 13 items covering socioeconomic as well as family- and parenting-related stressors. According to Baron and Kenny (1986) a series of logistic regression models was applied to investigate the role of psychosocial stress as a mediator on the relationship between single motherhood and smoking.

Results: About $44.0 \%$ of single mothers smoked daily, whereas only $26.2 \%$ of cohabitating mothers did. Single mothers reported more stress related to their economic situation, occupation and family than partnered mothers. Out of the original 13 stressors only 'conflicts with the partner or ex-partner' and 'financial worries' remained significant in explaining single mothers' higher risk of smoking. Against expectation, stress due to household requirements and family demands was associated with lower odds of single mothers' smoking. After controlling for psychosocial stress, the odds ratio of single mothers' moderate smoking ( $<20 \mathrm{cig}$./day) decreased slightly from 1.75 to 1.66 (explained fraction $X F=12.0 \%)$ and with respect to heavy smoking ( $\geq 20$ cig./day) more pronounced from 2.56 to 2.01 ( $X F=35.3 \%)$.

Conclusions: It can be stated that single mothers' heavy more than moderate smoking appeared to be mediated by perceived psychosocial stress. Out of all stressors considered, financial worries were of paramount significance in explaining single mothers' heavy smoking while some family-related stressors rather appeared to keep single mothers from smoking. Overall, a higher stress exposure explains partly but not sufficiently single mothers' increased smoking rates.
\end{abstract}

Keywords: Single mothers, Smoking rate, Psychosocial stress, Mediation

\section{Background}

In Germany every fifth family with a minor child is headed by a single parent, $90 \%$ of them are single mothers [1]. There is consistent evidence in Western countries that smoking prevalence in single mothers is higher than in married and cohabitating mothers [2-6]. A common explanation from a medical-sociological point of view would be that single mothers' increased tobacco use is due to their higher risk of socioeconomic disadvantages. A large body of literature has demonstrated that single mothers are more likely to be employed in lower status and lower

\footnotetext{
* Correspondence: Sperlich.Stefanie@mh-hannover.de

Hannover Medical School, Medical Sociology Unit, Carl-Neuberg-Str. 1, 30625 Hannover, Germany
}

paying jobs and to be at higher risks of poverty, poor psychosocial working conditions, work-family conflicts and financial hardships [7-10].

The conceptual framework of 'the social patterning of smoking' [11,12] suggests that individuals in a low socio-economic position experience more psychosocial stress and use smoking as a way of coping with difficult and stressful circumstances in order to come to terms with negative emotions. Numerous studies have confirmed this assumption revealing that stress is more often reported by smokers than non-smokers. Smokers experience higher levels of occupational, marital and financial stress and are also more affected by adverse life events such as divorce and unemployment [13]. 
Cohen et al. [14] found that four psychosocial factors were associated with women's smoking: a history of depression, marital conflicts, undesirable life events, and full time employment.

Psychosocial stress has been linked to the risks of smoking across all stages of smoking, that is, initiation, maintenance and relapse [13]. The strongest evidence has been found for the impact of financial hardship on smoking behaviour, holding in particular for single mothers [4,15-17]. However, Siapush et al. [6] pointed out that the association between single motherhood and smoking is not fully explained by socioeconomic disadvantages. In contrast to Dorsett and Marsh [18] they found a strong 'lone mother effect' on smoking after controlling for socioeconomic status. They argued that there are other factors closely related to the experience of being a lone mother, such as social isolation and loneliness, which play an important role in explaining single mothers' smoking behaviour. Jun and Arcevedo-Garcia [3] criticised that studies on single mothers rarely examined the influence of parenting on smoking. They could demonstrate that child care responsibilities significantly contributed to smoking patterns among white single mothers. All in all, previous studies suggest that psychosocial stress plays an important role in explaining smoking among single mothers. However, this evidence is mainly based on the effects of socio-economic hardships while less is known about the impact of parentingrelated stressors on single mothers' smoking. Similarly, there is little knowledge on how the impact of stress differs with respect to moderate and heavy smoking patterns. Against this background, this study aims to analyze the relevance of various stressors in explaining moderate as well as heavy smoking habits among single mothers. In more detail, the paper addresses the following questions (see Figure 1):

1. How does perceived psychosocial stress differ between single and partnered mothers?

2. Does psychosocial stress account for moderate and heavy smoking pattern and if so, does its effect hold for both single and partnered mothers?

3. Is single mothers' higher smoking rate mediated by psychosocial stress?

\section{Methods}

\section{Sample}

The sample consists of 3129 mothers with underage children (0-18 years of age) living in Germany. The cross-sectional survey was conducted by TNS Healthcare on behalf of the Department of Medical Sociology at Hannover Medical School. The ethics committee of Hannover Medical School approved the study. Data were collected in 2009 by means of a mail survey. The

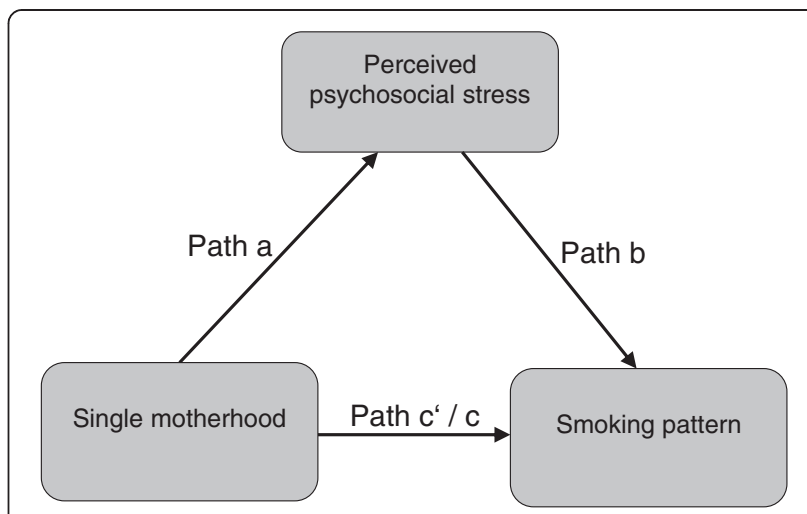

Figure 1 The Mediator Model of single motherhood on moderate and heavy smoking patterns. Path $\mathrm{c}$ indicates the total, $c^{\prime}$ the direct and path $a * b$ the indirect effect of $X$ on $Y$.

sample was derived from the Healthcare Access Panel comprising 75.000 households in total and 27.038 households with women having underage children. The Healthcare Access Panel is composed of respondents who have given their general consent to participate in surveys. Based upon an estimated response rate of 50 percent and a targeted case number of 2.500 mothers a total of 5.000 German mothers was selected randomly out of the panel. The gross sample was drawn according to predefined quotas, i.e. age of mother and youngest child, school education, marital status and number of children. The initial case number of young mothers ( $\leq 25$ years) had to be completed by another 107 cases in order to meet the quota. Of these 5107 mothers 3183 participated in the survey, corresponding to a return rate of $62.3 \%$. A total of 54 mothers was excluded subsequently because they did not meet the inclusion criteria (in particular youngest child was $>18$ years of age). The final sample consisted of 3129 mothers with 506 (16.8\%) out of them were single mothers. The number of missing values with respect to the key variables 'single vs. partnered mothers' $(3.6 \%)$ as well as smoking pattern $(0.8 \%)$ is relatively small. Hence, concerning these variables selection bias due to non-response are negligible. The sample was selected in proportion to the distributions of German federal states, school education, mother's age, and number of children. Subsequently, the cases were weighted in order to obtain data representative for German mothers (Table 1).

\section{Smoking pattern}

Smoking pattern was assessed by asking the women whether they currently smoke cigarettes. Pipe smoking was not assessed. The outcome variable 'current smoking status' includes three categories: (1) smoking daily (2) smoking occasionally (not daily) and (3) not smoking at all. If the women answered 'smoking daily', it was asked how many cigarettes they smoked per day. The 
Table 1 Sample characteristics of single and partnered mothers

\begin{tabular}{|c|c|c|c|c|c|}
\hline & \multicolumn{2}{|c|}{ Single mothers $n=506$} & \multicolumn{2}{|c|}{ Partnered mothers $n=2511$} & \multirow{2}{*}{$\begin{array}{l}\mathrm{Chi}^{2} \\
\mathrm{p} \text { value }\end{array}$} \\
\hline & $\mathrm{n}$ & $\%$ & $\mathbf{n}$ & $\%$ & \\
\hline Age (years) & & & & & 0.731 \\
\hline $20-29$ & 49 & 9.8 & 226 & 9.1 & \\
\hline 30-39 & 220 & 44.0 & 1068 & 42.8 & \\
\hline 40-49 & 207 & 41.4 & 1096 & 43.9 & \\
\hline $50-59$ & 24 & 4.8 & 106 & 4.2 & \\
\hline Missings & 6 & & 15 & & \\
\hline Age of the youngest child (years) & & & & & $<0.001$ \\
\hline $0-2$ & 30 & 6.0 & 437 & 17.6 & \\
\hline $3-5$ & 72 & 14.4 & 403 & 16.2 & \\
\hline $6-11$ & 187 & 37.5 & 789 & 31.7 & \\
\hline $12-15$ & 139 & 27.9 & 527 & 21.2 & \\
\hline $16-18$ & 71 & 14.2 & 331 & 13.3 & \\
\hline Missings & 7 & & 24 & & \\
\hline Number of children & & & & & $<0.001$ \\
\hline 1 & 293 & 60.7 & 842 & 35.8 & \\
\hline 2 & 145 & 30.0 & 1099 & 46.7 & \\
\hline $3+$ & 45 & 9.3 & 410 & 17.4 & \\
\hline Missings & 23 & & 160 & & \\
\hline Years of school education & & & & & 0.014 \\
\hline$\leq 9$ & 187 & 34.4 & 772 & 31.0 & \\
\hline 10 & 181 & 36.2 & 1037 & 41.6 & \\
\hline$\geq 12$ & 132 & 26.4 & 682 & 27.4 & \\
\hline Missings & 6 & & 20 & & \\
\hline Income & & & & & $<0.001$ \\
\hline$<60 \%$ median & 291 & 60.0 & 508 & 23.7 & \\
\hline$<100 \%$ median & 151 & 31.1 & 893 & 41.7 & \\
\hline$>100 \%$ median & 43 & 8.9 & 738 & 34.5 & \\
\hline Missings & 21 & & 372 & & \\
\hline Employment status & & & & & $<0.001$ \\
\hline Work $\leq 19$ hours/week & 71 & 14.5 & 442 & 23.6 & \\
\hline Work 20-37 hours/week & 200 & 40.8 & 922 & 37.2 & \\
\hline Work $\geq 38$ hours/week & 124 & 25.3 & 394 & 15.9 & \\
\hline Housewife/Maternity leave & 37 & 7.6 & 517 & 20.9 & \\
\hline Unemployed & 44 & 9.0 & 48 & 1.9 & \\
\hline Early retirement & 14 & 2.9 & 12 & 0.5 & \\
\hline Missings & 16 & & 34 & & \\
\hline
\end{tabular}

literature on smoking has no widely accepted criterion for separating light from heavy smokers. In line with Billings and Moos [19] we selected 20 cigarettes per day as a level at which tobacco dependence was probable and used this as a threshold for heavy smoking. The variable 'smoking pattern' was then defined as a three category outcome variable with non-smoking (currently not smoking at all), moderate (1-19 cig./day) and heavy smoking ( $\geq 20$ cig./day).

\section{Social and family related factors}

Socioeconomic status was measured with the following variables: school education, employment status and income. We categorized the household income based on needs- 
adjusted equivalence scales into three categories: $(1)<60 \%$ of the German median income, (2) between $60 \%$ and $100 \%$ of the German median income, and (3) above $100 \%$ of the German median income [20]. Single mothers are defined as mothers with at least one underage child living in the household without a partner, i.e. mothers cohabiting with a partner were not defined as single mothers but as 'partnered mothers'.

\section{Psychosocial stress}

Perceived psychosocial stress was measured by the questionnaire 'Parental Stress' (13 items) which proved to be relevant for mothers caring for young children [21,22]. Each item has five categories, ranging from 1 (not at all distressed/not applicable) to 5 (very strongly distressed). Mothers were asked how much they considered themselves as to be distressed with respect to the following stressors: (1) financial worries, (2) work-related adversity (including also stress due to unemployment), (3) partnerrelated problems (conflicts with current or former partner) (4) household requirements, (5) family demands (i.e. permanent availability for the family), (6) sole responsibility for children, (7) having a disabled or a chronically ill child, (8) child-related stress (e.g. child-rearing difficulties, conflicts in mother-child-interactions, problems at school), (9) having a family member in need of care (partner or a parent), (10) balancing job and family demands, (11) conflicts with other family members (e.g. parents, parents in law), (12) unwanted living alone/ loneliness and (13) stress due to lack of appreciation (less recognition of mother-role) (see Additional file 1).

\section{Further instruments}

Due to strong associations between smoking and mental health [23], we used the subscale 'depression' from the Hospital Anxiety and Depression Scale German Version (HADS-D) [24] in order to control for this possible confounder in our multivariate analysis. The subscale contains seven items, each ranging from 0 to 3 . We used the sum score ranging from 0 to 21 .

\section{Statistical analyses}

According to Baron and Kenny [25] psychosocial stress acts as a mediator for the relationship between single motherhood and smoking when the following conditions are met:

1. Being a single mother is associated with significantly increased rates of moderate and heavy smoking (Figure 1, path c). This condition was tested by regressing the dependent variables (moderate and heavy smoking) on the independent variable (single motherhood).

2. Being a single mother is associated with higher levels of perceived stress in daily life (Figure 1, path a). This presumption was examined by regressing the mediators (psychosocial stress) on the independent variable (single motherhood).

3. High levels of perceived stress in daily life are associated with higher rates of moderate as well as heavy smoking pattern (Figure 1, path b). This was analyzed by regressing the dependent variables (moderate and heavy smoking pattern) on the mediators (psychosocial stress). In order to analyze whether the effects of stress on smoking hold for both single and partnered mothers, interaction effects between single motherhood and psychosocial stress were computed.

4. The effect of single motherhood on moderate and heavy smoking pattern must be smaller in presence of psychosocial stress (Figure 1, path c'< path c). This was tested by regressing the dependent variables (moderate and heavy smoking pattern) on both the independent variable (single motherhood) and psychosocial stress (mediators). A stepwise logistic regression analysis (method: forward selection, likelihood quotient) with two blocks was computed for moderate as well as heavy smoking pattern. Block 1 as the baseline model contains the total effect of single motherhood adjusted for maternal age, age of youngest child and depression (HADS-D). Block 2 adds the stressors meeting the conditions to establish mediation (see above). The decline in odds ratios from block 1 to 2 reflects the influence of psychosocial stress on single mothers' smoking pattern. The percentage of single mothers' odds for moderate and heavy smoking explained by psychosocial stress (explained fractions XF) was calculated using the common formula [26]: $\mathrm{XF}=(\mathrm{OR}$ baseline model $-\mathrm{OR}$ extended model $) /$ ((OR baseline model) -1$)$.

All conditions were tested using binary logistic regression analyses with the following dichotomous variables: Psychosocial stress $=$ high stress (categories 4 and 5 of response format) vs. low stress (categories 1 to 3 of response format), single motherhood = yes vs. no, moderate/heavy smoking=yes vs. not smoking. For testing conditions 1 to 3 , odds ratios were adjusted for maternal age and age of the youngest child. Pearson's $x^{2}$ test was used for testing the statistical significance of differences between single and partnered mothers with respect to sample characteristics. Statistical analyses were performed with SPSS version 19.0.

\section{Results}

Comparison of single and partnered mothers

Compared to partnered mothers (mean age $39.2 \pm$ 6.5 ), single mothers (mean age $38.6 \pm 6.9$ ) were more 
Table 2 Effect of single motherhood on smoking

\begin{tabular}{|c|c|c|c|c|c|c|}
\hline \multirow[b]{2}{*}{ Smoking status (current) } & \multicolumn{2}{|c|}{ Single mothers } & \multicolumn{2}{|c|}{ Partnered mothers } & \multicolumn{2}{|c|}{ Single motherhood } \\
\hline & $n$ & $\%$ & $\mathbf{n}$ & $\overline{\%}$ & OR & $\mathrm{Cl} 95 \%$ \\
\hline Daily smoking (at least 1 cig./day) & 220 & 44.0 & 654 & 26.2 & 2.11 & $1.70-2.60$ \\
\hline Heavy smoking ( $\geq 20$ cig./day) & 96 & 19.2 & 211 & 8.4 & 2.87 & 2.16-3.81 \\
\hline Moderate smoking (1-19 cig./day) & 124 & 24.8 & 443 & 17.7 & 1.73 & $1.36-2.20$ \\
\hline Occasional smoking (not daily) & 34 & 6.8 & 126 & 5.0 & 1.69 & $1.20-2.56$ \\
\hline Non-smoking & 246 & 49.2 & 1719 & 68.8 & Ref. & \\
\hline
\end{tabular}

Notes: Results of logistic regression analysis adjusted for mother's age and age of youngest child. Single mothers $(n=506)$, partnered mothers $(n=2511)$. Reference category 'single motherhood' = partnered mothers. 'Ref.' means reference category. Bold values indicate significant effects.

likely to have only one child and were less likely to have an infant child ( 0 to 2 years). With respect to their socioeconomic status single mothers showed lower educational levels and they were at higher risk of poverty $(<60 \%$ median income). In addition, single mothers were more likely to be full-time employed as well as unemployed and looking for a job compared to partnered mothers.

\section{Effect of single motherhood on smoking}

The percentage of single mothers who smoked daily was $44.0 \%$ compared to $26.2 \%$ among partnered mothers (Table 2). This corresponds to an odds ratio of $\mathrm{OR}=$ 2.11 for daily smoking among single mothers. Most pronounced is the difference in smoking pattern with respect to heavy smoking: nearly every fifth single mother (19.2\%) smoked at least 20 cigarettes a day, whereas this applied only to $8.4 \%$ of partnered mothers $(\mathrm{OR}=2.87)$. Also moderate smoking patterns $(\mathrm{OR}=1.73)$ as well as occasional smoking $(\mathrm{OR}=1.69)$ were higher in single than in partnered mothers.

Effect of single motherhood on perceived psychosocial stress Single mothers perceived significantly higher stress levels as compared to their cohabitating counterparts (Table 3). This holds for structural problems ('financial worries' and 'career-related stress') as well as stress related to parenting ('child-rearing difficulties), marital difficulties ('conflicts with the partner or former partner') and familyrelated stress ('sole responsibility for the children', 'household requirements', 'family demands', 'balancing family and job demands' and 'little recognition of family work'). The difference between single and partnered mothers was most pronounced with respect to the stressors 'unwanted living alone/loneliness' $(\mathrm{OR}=19.49)$, 'sole responsibility for the child/ren' $(\mathrm{OR}=8.03)$, 'financial worries' $(\mathrm{OR}=3.55)$ and stress related to 'career situation/ unemployment' $(\mathrm{OR}=2.89)$. No significant differences in stress levels between single and partnered mothers

Table 3 Effect of single motherhood on perceived psychosocial stress

\begin{tabular}{|c|c|c|c|c|c|c|}
\hline \multirow[b]{2}{*}{ High psychosocial stress due to.... } & \multicolumn{2}{|c|}{ Single mothers } & \multicolumn{2}{|c|}{ Partnered mothers } & \multicolumn{2}{|c|}{ Single motherhood } \\
\hline & $\%$ & $\mathbf{n}$ & $\%$ & $\bar{n}$ & OR & $\mathrm{Cl} 95 \%$ \\
\hline financial worries & 51.9 & 261 & 23.1 & 575 & 3.55 & $2.89-3.58$ \\
\hline career situation/unemployment & 38.5 & 193 & 17.7 & 441 & 2.89 & 2.34-3.58 \\
\hline conflicts with the partner or ex-partner & 29.4 & 148 & 13.9 & 346 & 2.71 & 2.15-3.41 \\
\hline household requirements & 29.5 & 148 & 25.0 & 623 & 1.45 & 1.17-1.81 \\
\hline family demands & 34.1 & 171 & 29.9 & 726 & 1.51 & $1.22-1.86$ \\
\hline sole responsibility for the child/ren & 56.4 & 238 & 15.1 & 376 & 8.03 & $6.48-9.99$ \\
\hline a disabled or chronically ill child & 5.8 & 29 & 4.6 & 114 & 1.30 & $0.85-2.00$ \\
\hline child-rearing difficulties & 28.3 & 142 & 17.2 & 428 & 1.91 & $1.53-2.40$ \\
\hline a family member in need of care & 6.0 & 30 & 6.5 & 160 & 0.93 & $0.62-1.41$ \\
\hline balancing family and job demands & 27.5 & 139 & 15.3 & 380 & 2.36 & $1.82-2.90$ \\
\hline conflicts with other family members & 12.0 & 60 & 11.8 & 294 & 1.03 & $0.76-1.39$ \\
\hline unwanted living alone/loneliness & 31.5 & 159 & 2.3 & 58 & 19.49 & 13.94-27.24 \\
\hline little recognition of family work & 25.6 & 129 & 15.8 & 354 & 1.88 & $1.48-2.38$ \\
\hline
\end{tabular}

Notes: Results of logistic regression analysis adjusted for mother's age and age of youngest child. High psychosocial stress $=$ categories 4 and 5 of response format (reference categories $=1$ to 3 ), reference category of 'single motherhood' = partnered mothers. Bold values indicate significant effects. 
Table 4 Effects of perceived psychosocial stress on moderate and heavy smoking pattern

\begin{tabular}{|c|c|c|c|c|c|c|c|c|c|c|}
\hline \multirow[b]{2}{*}{ High psychosocial stress due to... } & \multicolumn{2}{|c|}{ Non- smoking } & \multicolumn{2}{|c|}{ Moderate smoking } & \multicolumn{2}{|c|}{ Heavy smoking } & \multicolumn{2}{|c|}{ Moderate smoking } & \multicolumn{2}{|c|}{ Heavy smoking } \\
\hline & $\%$ & n & $\%$ & n & $\%$ & $\bar{n}$ & OR & $\mathrm{Cl} 95 \%$ & OR & $\mathrm{Cl} 95 \%$ \\
\hline financial worries & 23.5 & 470 & 33.3 & 197 & 44.8 & 147 & 1.22 & $0.78-1.89$ & 2.54 & $1.53-4.20$ \\
\hline career situation/unemployment & 18.3 & 363 & 24.4 & 145 & 31.9 & 105 & 1.39 & $1.06-1.81$ & 1.64 & $1.15-2.33$ \\
\hline conflicts with the partner or ex-partner & 14.5 & 290 & 19.0 & 113 & 22.4 & 73 & 1.47 & $1.10-1.97$ & 1.69 & $1.15-2.49$ \\
\hline sole responsibility for the child/ren & 19.9 & 395 & 25.4 & 151 & 34.3 & 113 & 1.47 & 1.11-1.95 & 1.63 & $1.12-2.38$ \\
\hline child-rearing difficulties & 18.3 & 361 & 18.4 & 109 & 27.8 & 91 & 1.02 & $0.76-1.35$ & 1.54 & $1.08-2.19$ \\
\hline unwanted living alone/loneliness & 6.1 & 121 & 6.4 & 38 & 16.3 & 53 & 1.14 & $0.55-2.34$ & 2.99 & $1.48-6.04$ \\
\hline little recognition of family work & 16.2 & 324 & 15.8 & 94 & 27.2 & 89 & 1.13 & $0.84-1.52$ & 2.19 & $1.55-3.09$ \\
\hline a family member in need of care & 6.0 & 118 & 4.9 & 29 & 11.0 & 36 & 0.96 & $0.61-1.52$ & 2.10 & $1.29-3.43$ \\
\hline conflicts with other family members & 11.4 & 226 & 10.6 & 63 & 16.1 & 52 & 1.16 & $0.84-1.60$ & 1.60 & $1.06-2.41$ \\
\hline household requirements & 26.3 & 523 & 22.3 & 132 & 27.7 & 91 & 1.07 & $0.84-1.37$ & 1.19 & $0.85-1.66$ \\
\hline family demands & 29.8 & 593 & 29.4 & 175 & 29.5 & 97 & 1.27 & $1.00-1.60$ & 1.29 & $0.93-1.78$ \\
\hline a disabled or chronically ill child & 4.8 & 95 & 4.7 & 28 & 5.8 & 19 & 1.12 & $0.69-1.83$ & 0.86 & $0.41-1.79$ \\
\hline balancing family and job demands & 16.9 & 336 & 16.4 & 97 & 21.0 & 69 & 1.23 & $0.92-1.64$ & 1.23 & $0.83-1.83$ \\
\hline
\end{tabular}

Notes: Results of logistic regression analysis adjusted for single motherhood, interaction term between single motherhood and stressors, mother's age and age of youngest child. Moderate smoking $=<20$ cig./day, heavy smoking $=\geq 20$ cig./day (reference category $=$ non-smoking), high psychosocial stress $=$ categories 4 and 5 of response format (reference categories $=1$ to 3 ), OR = odds ratio, $\mathrm{Cl} 95 \%=95 \%$ confidence interval. Bold values indicate significant effects.

were found with respect to having 'a disabled or chronically ill child', stress caused by 'a family member in need of care' and stress related to 'conflicts with other family members'.

\section{Effects of perceived psychosocial stress on moderate and heavy smoking pattern}

The first four stressors displayed in Table 4, namely 'financial worries', stress due to 'career situation/unemployment', 'conflicts with the partner or ex-partner' and 'sole responsibility for the children' were associated with increased rates of moderate as well as heavy smoking. Odds ratios were more pronounced for the outcome 'heavy smoking pattern' (OR ranging between 1.63 and 2.54) as compared to 'moderate smoking pattern' (OR ranging between 1.22 and 1.47). The next five stressors showed a significant effect on heavy, but not on moderate smoking habits. This was the case for 'childrearing difficulties' (OR= 1.54), 'unwanted living alone/loneliness' $(\mathrm{OR}=2.99)$, 'little recognition of family work' (OR $=2.19)$, 'a family member in need of care' $(\mathrm{OR}=2.10)$ and 'conflicts with other family members' $(\mathrm{OR}=1.60)$. The last four stressors showed no significant effect on smoking, neither on moderate nor on heavy smoking pattern. This applied to 'household requirements', 'family demands', 'a disabled or chronically ill child' and 'balancing family and job demands'.

\section{Interaction effects between single motherhood and stress} on smoking

In order to analyze if the observed relationships between stress and smoking held for both single as well as partnered mothers, interaction effects between single motherhood and stress on smoking were computed by means of logistic regression analysis (Table 5). Most of the stressors effecting moderate as well as heavy smoking pattern (Table 4) showed no significant interaction with single motherhood. The exception was 'sole responsibility for the child/ren' with an OR $=0.46$, indicating that this stressor is significantly less relevant in explaining single mothers' moderate smoking as compared to partnered mothers. As indicated by odds ratios below 1 also the effects of 'unwanted living alone/loneliness' and 'little recognition of family work' on heavy smoking (Table 4) revealed to be less important in single mothers. Similarly, family-related stressors, namely 'conflicts with other family members', 'household requirements', 'family demands', 'a disabled or chronically ill child' and 'balancing family and job demands' showed significant interaction terms, indicating that they were less applicable in explaining single mothers' smoking, in particular their moderate smoking pattern.

Impact of psychosocial stress on mothers' smoking status Finally, we examined the extent to which single mothers' higher smoking rates could be attributed to their higher stress levels using forward stepwise logistic regression analysis (Table 6). Our analysis included all psychosocial stressors showing a significant association with single motherhood (Table 3 ) as well as smoking (Table 4) in the predicted direction. Stressors showing a significant interaction with single motherhood that point in the opposite direction of decreased odds of smoking in single mothers ('Table 5) were 
Table 5 Interaction effects between single motherhood and stress on moderate and heavy smoking pattern

\begin{tabular}{|c|c|c|c|c|}
\hline \multirow[b]{2}{*}{ High psychosocial stress due to... } & \multicolumn{2}{|c|}{ Moderate smoking } & \multicolumn{2}{|c|}{ Heavy smoking } \\
\hline & OR & $\mathrm{Cl} 95 \%$ & OR & $\mathrm{Cl} 95 \%$ \\
\hline financial worries * single motherhood & 1.37 & $0.82-2.27$ & 0.88 & $0.48-1.59$ \\
\hline career situation/unemployment ${ }^{*}$ single motherhood & 0.76 & $0.45-1.29$ & 1.02 & $0.56-1.87$ \\
\hline conflicts with the partner or ex-partner * single motherhood & 0.79 & $0.44-1.39$ & 0.82 & $0.43-1.56$ \\
\hline sole responsibility for the child/ren * single motherhood & 0.46 & $0.27-0.78$ & 0.83 & $0.44-1.54$ \\
\hline child-rearing difficulties * single motherhood & 0.74 & $0.41-1.33$ & 0.92 & $0.49-1.70$ \\
\hline unwanted living alone/loneliness * single motherhood & 0.39 & $0.16-0.97$ & 0.40 & 0.17-0.95 \\
\hline little recognition of family work * single motherhood & 0.47 & $0.25-0.89$ & 0.52 & $0.27-0.97$ \\
\hline a family member in need of care ${ }^{*}$ single motherhood & 0.60 & $0.18-2.02$ & 0.91 & $0.33-2.45$ \\
\hline conflicts with other family members * single motherhood & 0.37 & 0.14-0.96 & 0.83 & $0.37-1.84$ \\
\hline household requirements * single motherhood & 0.32 & $0.18-0.59$ & 0.66 & $0.36-1.22$ \\
\hline family demands * single motherhood & 0.45 & $0.26-0.76$ & 0.49 & $0.27-0.90$ \\
\hline a disabled or chronically ill child * single motherhood & 0.18 & 0.04-0.83 & 1.08 & $0.34-3.44$ \\
\hline balancing family and job demands * single motherhood & 0.33 & $0.18-0.62$ & 0.85 & $0.44-1.62$ \\
\hline
\end{tabular}

Notes: Results of logistic regression analysis adjusted for single motherhood (main effect), mother's age and age of youngest child. Bold values indicate significant effects. See Table 3 for explanations of abbreviations.

not included in the analysis. With respect to moderate smoking the conditions for mediation were only met in case of 'conflicts with the partner or expartner' and stress due to 'career situation/unemployment'. With respect to heavy smoking this holds to 'financial worries', 'stress due to 'career situation/ unemployment', 'conflicts with the partner or ex-partner', 'sole responsibility for the children' and 'child-rearing difficulties'.
Block 1 displayed single mothers' odds of moderate $(\mathrm{OR}=1.75)$ and heavy smoking pattern $(\mathrm{OR}=2.56)$ adjusted for mothers' age, age of youngest child and depression. Stepwise regression (Block 2) revealed that 'conflicts with the partner or ex-partner' is the only significant predictor in explaining moderate smoking pattern, while stress due to 'career situation/unemployment' failed to reach statistical significance in Block 2 . Odds of moderate smoking continuously increased with

Table 6 Changes in odds ratios for smoking in single mothers after controlling for psychosocial stress

\begin{tabular}{|c|c|c|c|c|c|c|c|}
\hline \multirow[b]{2}{*}{ Moderate smoking } & \multicolumn{3}{|c|}{ Block $1^{1}$} & \multicolumn{4}{|c|}{ Block 2} \\
\hline & OR & KI 95\% & $\mathrm{R}^{2}$ & OR & KI 95\% & $\mathrm{XF}$ & $\mathrm{R}^{2}$ \\
\hline single motherhood (yes) & 1.75 & $1.35-2.25$ & .043 & 1.66 & $1.28-2.15$ & $12.0 \%$ & .051 \\
\hline \multicolumn{8}{|c|}{ conflicts with the partner or ex-partner } \\
\hline not at all/not applicable & & & & Ref. & & & \\
\hline slightly & & & & 0.91 & $0.71-1.17$ & & \\
\hline moderately & & & & 1.37 & $1.02-1.83$ & & \\
\hline strongly & & & & 1.45 & $1.01-2.08$ & & \\
\hline very strongly & & & & 1.58 & $1.07-2.35$ & & \\
\hline \multicolumn{8}{|l|}{ Heavy smoking } \\
\hline single motherhood (yes) & 2.56 & $1.90-3.45$ & .097 & 2.01 & $1.47-2.75$ & $35.3 \%$ & .131 \\
\hline \multicolumn{8}{|l|}{ financial worries } \\
\hline not at all/not applicable & & & & Ref. & & & \\
\hline slightly & & & & 1.34 & $0.86-2.10$ & & \\
\hline moderately & & & & 1.78 & $1.15-2.77$ & & \\
\hline strongly & & & & 1.92 & $1.18-3.12$ & & \\
\hline very strongly & & & & 4.33 & $2.67-7.01$ & & \\
\hline
\end{tabular}

Notes: ${ }^{1}$ Results of stepwise logistic regression analysis adjusted for mother's age, depression (mean score single mothers: $8.59 \pm 4.05$ and partnered mothers: $7.23 \pm 3.79$ ) and age of youngest child, XF = percentage of smoking explained by the stressor, Pseudo $R^{2}=$ Nagelkerke. Reference category is indicated by 'Ref.'. Bold values indicate significant effects. 
stress level from $\mathrm{OR}=0.91$ ('slightly distressed due to 'conflicts with the partner or ex-partner') to $\mathrm{OR}=1.58$ ('very strongly distressed'). By entering this stressor in the model, odds ratios for single mothers' moderate smoking pattern decreased slightly from 1.75 to 1.66 . This corresponded to a change in the odds ratios of $12.0 \%$.

'Financial worries' proved to be most important in predicting single mothers' heavy smoking pattern. Odds of heavy smoking climbed up to $\mathrm{OR}=4.33$ when women reported to be 'very strongly' distressed by financial worries. Entering this stressor in Block 2 resulted in a substantially decrease of OR for single mothers' heavy smoking pattern from 2.56 to 2.01, representing a change of $35.3 \%$ explained by this stressor. All other stressors, namely 'career situation/unemployment,' conflicts with the partner or ex-partner', 'sole responsibility for the child/ren' and 'child-rearing difficulties' failed to reach statistical significance in the multivariate model and thus made no contribution in explaining single mothers' odds for heavy smoking.

\section{Discussion}

In line with the current state of research [2-6] our findings confirmed higher smoking rates among single as compared to partnered mothers, holding in particular for heavy smoking pattern. Against this background, this study aimed to analyze whether perceived psychosocial stress acts as a mediator and accounts for the relationship between single motherhood and smoking. According to Baron and Kenny [25] psychosocial stressors function as a mediator when they are systematically varied in dependency of the status 'single' or 'partnered' mothers (condition 1) and when they in turn significantly effect smoking pattern (condition 2).

\section{Perceived psychosocial stress in single and partnered mothers}

With respect to the first condition, our analysis has shown to be in accordance with many other studies [7-10] indicating that single mothers are at higher risk of poverty and reported considerably higher levels of financial and occupational stress as compared to partnered mothers. We also found single mothers facing higher levels of family-, marital- as well as parenting-related stress and also higher levels of stress related to balancing family and job demands. In this context, Avison et al. [27] pointed out that single mothers are more likely to report that family demands interfere with paid work and vice versa. They see this influence as an example of the ways in which the structure of families and the broader social structure of society interact to create stress among single mothers. Our study confirms these considerations, indicating that single mothers encounter significantly higher stress levels in both social roles: caregiver as well as breadwinner.

\section{Effects of psychosocial stress on moderate and heavy smoking pattern}

We also found that smoking rates increased with single mothers' levels of perceived psychosocial stress, confirming the second condition of a mediator-effect. In line with previous studies [4,15-17] we found a strong effect of financial worries and job-related stress in particular on the risk of heavy smoking. While the effect of socioeconomic hardship on smoking has been well researched by now, little is known about the role of family- and parenting-related stress on single mothers' smoking patterns. The few available studies suggest that child care responsibilities and marital stress imply an independent risk of smoking among women [3,14,28,29]. Based on this evidence, we hypothesized that single mothers facing high levels of marital-, parenting- and family-related stress are more likely to smoke than single mothers with lower stress levels. In line with this assumption we found a strong effect of marital conflicts ('conflicts with the partner or ex-partner) on moderate as well as heavy smoking pattern. As expected, also 'sole responsibility for the child/ren' was associated with moderate as well as heavy smoking pattern. However, scoring high on some other family-related stressors (e.g. household requirements and family demands) showed no significant association with smoking, neither with moderate nor with heavy smoking pattern. Searching for explanations we noticed that stress levels of these stressors increased while smoking rates decreased with higher levels of school education. Hence, there is some evidence that educational attainment moderate the effect of stress on smoking. However, subsequent research is needed to follow this track and empirically substantiate this assumption.

In contrast to a number of studies suggesting a linear relationship between stress level and smoking [13] we found some stressors being associated only with heavy, but not with moderate smoking. This was the case for stress due to 'child-rearing difficulties', 'little recognition of family work', 'family member in need of care', 'conflicts with other family members' and 'unwanted living alone/ isolation'. This finding supports a differentiation between moderate and heavy smoking suggesting that heavy smoking women face not only higher levels of stress, but also different kinds of stress.

Surprisingly, we found significant interaction effects between single motherhood and stress on smoking in a way that among single mothers some family-related stressors were not only irrelevant but rather associated with significantly reduced odds of foremost moderate smoking habits. This may suggest that some familyrelated stressors such as family demands and household 
requirements keep single mothers away from smoking. Similarly, we found significant interaction effects with respect to the stressors 'unwanted living alone/loneliness' and 'little recognition of family work'. These findings demonstrate that the effect of these stressors on heavy smoking only holds in partnered mothers and revealed to be largely irrelevant in explaining single mothers' heavy smoking pattern. In principle, this finding indicates that the association between stress and smoking differs between single and partnered mothers, pointing to a moderator-effect of single motherhood on the relationship between stress and smoking. This result may provide a starting point for further analysis with the aim of combining mediation and moderation analysis in explaining single mothers' higher smoking rates.

\section{Contribution of psychosocial stress in explaining single mothers' smoking patterns}

Our findings revealed that out of the original 13 stressors only two remained relevant in explaining single mothers' higher odds of smoking. First, this was stress due to 'conflicts with the partner or ex-partner' which could explain $12 \%$ of single mothers' higher odds for moderate smoking. Financial worries, secondly, turned out to be the most important predictor in explaining single mothers' heavy smoking pattern. This stressor alone explained $35.3 \%$ of their higher odds for heavy smoking. All other stressors failed to reach the conditions for being a mediator or showed no significant effect on smoking in the final model. The association between single motherhood and moderate as well as heavy smoking remained significant after controlling for psychosocial stress. Accordingly, the 'single mother-effect' on smoking could in part but not completely be attributed to their higher stress exposure.

The finding that the stressors 'career situation/ unemployment', 'conflicts with the partner or ex-partner,' 'sole responsibility for the child/ren' and 'child-rearing difficulties' were significantly associated with heavy smoking in the univariate analysis but failed to reach statistical significance in the multivariate model might be attributed to the fact that these stressors are correlated. Indeed, as deeper investigations revealed, these stressors showed significant correlations, reaching Spearman-Rho coefficients ranging from 0.28 to 0.39 . We also found significant correlations between these stressors and financial worries (Spearman-Rho coefficients ranging from 0.31 to 0.44 ), indicating that financial worries also cause increased stress levels, related for example to 'child-rearing difficulties' and 'conflicts with the partner or ex-partner'. Our results underline the relevance of tackling social disadvantages among single mothers as these efforts not only enhance their material living conditions but also have positive effects on their psychosocial stress level in general. All in all our findings emphasize the need for smoking-cessation programs which not only offer advice on how to quit smoking but also address social and financial stressors that place single mothers at high risk of smoking.

\section{Limitations}

It has to be noted that firm conclusions cannot be drawn on the causal relationship between smoking and stress as the data used were cross-sectional. According to Siahpush et al. [17] it can be assumed that smoking may also create financial stress, particularly among socially disadvantaged single mothers. In addition, we could not adjust for further possible confounders such as urban versus rural residence or physical activity which may contribute to single mothers' higher smoking rates. It has also to be mentioned that the questionnaire used in this study did not provide information about the smoking history of respondents and their past attempts to quit smoking. As we only asked for current daily stressors we also did not know whether the stressful life situation was acute or chronic. Umberson et al. [30] emphasized the importance of merging stress and life course perspectives to elaborate on the impact of stress on health-related behaviour. This approach is promising for providing deeper insights on trajectories of single mothers' stress unfolding over the life course and on the question whether their higher stress experience is transitory or stable over time.

\section{Conclusions}

Single mothers' daily stress experiences are not limited to socioeconomic disadvantages but also include parentingand family-related strains. The impact of stress on single mothers' smoking differs between moderate and heavy smoking pattern: while the stressor 'conflicts with the partner or ex-partner' turned out to be most important in predicting single mothers' moderate smoking, 'financial worries' accounted most in explaining their heavy smoking pattern. Our results support a differentiation between moderate and heavy smoking suggesting that heavy more than moderate smoking is mediated by psychosocial stress. Overall, a higher stress exposure explains partly but not completely single mothers' increased smoking rates.

\section{Additional file}

Additional file 1: Questionnaire Parental Stress.

\section{Competing interests}

We declare that we have no conflicts of interest in the authorship or publication of this contribution. We can exclude any financial and non-financial competing interests. 


\section{Authors' contribution}

SS has made substantial contributions to the concept and design and performed the statistical analysis and wrote the manuscript. MNM participated in the design of the study and helped to draft the manuscript. DN has been involved in revising the manuscript critically for important intellectual content. All authors read and approved the final manuscript.

\section{Acknowledgements}

This study was funded by the German Research Fundation (DFG) under Grant Number GE 1167/7-1. Publication costs are granted by the DFG project 'open access publishing' at Medical School Hannover.

Received: 22 January 2013 Accepted: 26 November 2013 Published: 5 December 2013

\section{References}

1. German Federal Statistics Office: Alleinerziehende in Deutschland 2010. Wiesbaden: Ergebnisse des Mikrozensus; 2010.

2. Graham H, Hawkins SS, Law C: Lifecourse influences on women's smoking before, during and after pregnancy. Soc Sci Med 2010, 70:582-587.

3. Jun HJ, Acevedo-Garcia D: The effect of single motherhood on smoking by socioeconomic status and race/ethnicity. Soc Sci Med 2007, 65:653-666.

4. Rahkonen O, Laaksonen M, Karvonen S: The contribution of lone parenthood and economic difficulties to smoking. Soc Sci Med 2005 61:211-216.

5. Siahpush M: Why is lone-motherhood so strongly associated with smoking? Aust N Z J Public Health 2004, 28:37-42.

6. Siahpush M, Borland R, Scollo M: Health inequalities: prevalence and socio-economic correlates of smoking among lone mothers in Australia. Aust N Z J Public Health 2002, 26:132-135.

7. Dziak E, Janzen B, Muhajarine $\mathrm{N}$ : Inequalities in the psychological well-being of employed, single and partnered mothers: the role of psychosocial work quality and work-family conflict. Int J Equity Health 2010, 9:6.

8. Goedhart G, van der Wal MF, Cuijpers P, Bonsel GJ: Psychosocial problems and continued smoking during pregnancy. Addict Behav 2009, 34:403-406.

9. Young $L E$, James $A D$, Cunningham SL: Lone motherhood and risk for cardiovascular disease: the national population health survey (NPHS), 1998-99. Can J Public Health 2004, 95:329-335.

10. Targosz S, Bebbington P, Lewis G, Brugha T, Jenkins R, Farrell M, Meltzer H: Lone mothers, social exclusion and depression. Psychol Med 2003, 33:715-722.

11. Dunn JR: Health behavior vs the stress of low socioeconomic status and health outcomes. JAMA 2010, 303:1199-1200.

12. Mackenbach J: Health inequalities: Europe in profile, An independent expert report commissioned by the UK Presidency of the EU. London: Department of Health; 2006. http://ec.europa.eu/health/ph_determinants/ socio_economics/documents/ev_060302 rd06 en.pdf.

13. Kassel JD, Stroud LR, Paronis CA: Smoking, stress, and negative affect: correlation, causation, and context across stages of smoking. Psychol Bull 2003, 129:270-304.

14. Cohen S, Schwartz JE, Bromet EJ, et al: Mental health, stress, and poor health behaviors in two community samples. Prev Med 1991, 20:306-315.

15. Greaves L, Hemsing N: Women and tobacco control policies: Social-structural and psychosocial contributions to vulnerability to tobacco use and exposure. Drug Alcohol Depend 2009, 104(Supplement 1):S121-S130.

16. Jun H-J, Subramanian SV, Gortmaker S, Kawachi I: Socioeconomic disadvantage, parenting responsibility, and women's smoking in the United States. Am J Public Health 2004, 94:2170-2176.

17. Siahpush M, Borland R, Scollo M: Smoking and financial stress. Tob Control 2003, 12:60-66.

18. Dorsett R, Marsh A: The health trap: poverty, smoking and lone parenthood. London (UK): Policy Studies Institute; 1998

19. Billings $\mathrm{AG}$, Moos $\mathrm{RH}$ : Social-environmental factors among light and heavy cigarette smokers: a controlled comparison with nonsmokers. Addict Behav 1983, 8:381-391.

20. Atkinson A, Cantillon B, Marlier E, Nolan B: Social indicators: the EU and social inclusion. Oxford: University Press; 2002.

21. Sperlich S, Arnhold-Kerri S, Geyer S: What accounts for depressive symptoms among mothers? The impact of socioeconomic status, family structure and psychosocial stress. Int J Public Health 2011, 56:385-396.
22. Sperlich S, Arnhold-Kerri S, Geyer S: Social living conditions and health among mothers in Germany: findings from a population sample. Bundesgesundheitsblatt Gesundheitsforschung Gesundheitsschutz 2011, 54:735-744.

23. Mykletun A, Overland S, Aarø LE, Liabø H-M, Stewart R: Smoking in relation to anxiety and depression: evidence from a large population survey: the HUNT study. Eur Psychiatry 2008, 23:77-84.

24. Herrmann C, Buss U, Snaith RP: HADS-D - Hospital Anxiety and Depression Scale - Deutsche Version: Ein Fragebogen zur Erfassung von Angst und Depressivität in der somatischen Medizin. Bern: Hans Huber; 1995.

25. Baron RM, Kenny DA: The moderator-mediator variable distinction in social psychological research: conceptual, strategic, and statistical considerations. J Pers Soc Psychol 1986, 51:1173-1182.

26. Schrijvers CTM, van de Mheen HD, Stronks K, Mackenbach JP: Socioeconomic inequalities in health in the working population: the contribution of working conditions. Int J Epidemiol 1998, 27:1011-1018.

27. Avison WR, Ali J, Walters D: Family structure, stress, and psychological distress: a demonstration of the impact of differential exposure. $J$ Health Soc Behav 2007, 48:301-317.

28. Graham H: Cigarette smoking: a light on gender and class inequality in Britain? J Soc Policy 1995, 24:509-527.

29. Graham H: Women's smoking and family health. Soc Sci Med 1987, 25:47-56.

30. Umberson D, Liu H, Reczek C: Stress and health behaviour over the life course. Adv Life Course Res 2008, 13:19-44.

doi:10.1186/1471-2458-13-1125

Cite this article as: Sperlich et al:: The effect of psychosocial stress on single mothers' smoking. BMC Public Health 2013 13:1125.

\section{Submit your next manuscript to BioMed Central and take full advantage of:}

- Convenient online submission

- Thorough peer review

- No space constraints or color figure charges

- Immediate publication on acceptance

- Inclusion in PubMed, CAS, Scopus and Google Scholar

- Research which is freely available for redistribution

Submit your manuscript at www.biomedcentral.com/submit
C Biomed Central 